\title{
Pengaruh Variasi Ketinggian Muka Air dan Ketebalan Batu Bata Interlock Terhadap Stabilitas Lereng Bangunan Pelindung Tebing
}

\author{
Agus Hari Wahyudi), Adi Yusuf Muttaqien ${ }^{2}$, dan Arfan Yosanurahman ${ }^{3}$ \\ 1) Pengajar Fakultas Teknik, Prodi Teknik Sipil, Universitas Sebelas Maret \\ 2) Pengajar Fakultas Teknik, Prodi Teknik Sipil, Universitas Sebelas Maret \\ 3) Mahasiswa Fakultas Teknik, Prodi Teknik Sipil, Universitas Sebelas Maret \\ Jl. Ir. Sutami 36A, Surakarta 57126; Telp.0271-634524. Email: arfan32@gmail.com
}

\begin{abstract}
Kedung Keris River is a river that forms meanders. This type of river has a problem that often occurs, namely erosion or scour on river banks based on the bend area outside the river. To protect the slope, a slope protection was made. One of the environmental friendly materials for protecting slope that will be research is Interlock bricks made from grilled red soil. Interlock brick is a wall material that has hooks on its sides. This study discusses variations in water level and thickness of interlock bricks for slope stability of the slope proection. This research is a quantitative study through research conducted at the Soil Mechanics Laboratory and Materials Mechanics Laboratory of Sebelas Maret University. The parameters sought consist of soil and interlock brick parameters. Material parameters include density, cohesion and inner shear angle. Then from the parameters generated will be modeling using geoslope software which will produce slope safety factor from water level and thickness of Interlock bricks variation. Based on modeling using hec ras and geoslope software, the height of the slope protection is 7 meters. From the influence of the height section the slope above, the maximum sfaety factor result at the height section the slope above 2.5 meters is 1,451. From the influence of interlock brick thickness on slope stability, the maximum safety factor results at 3 brick thickness is 1.459. From the influence of variations water level on slope stability, the minimum safety factor results at 2 meters from the foundation is 1,347.
\end{abstract}

Keyword : water level variation, interlock brick thickness, slope stability, slope protection

\begin{abstract}
Abstrak :
Sungai Kedung Keris merupakan sungai yang berbentuk meander. Sungai tipe ini memiliki masalah yang sering dihadapi yaitu erosi atau gerusan pada tebing sungai terutama di daerah tikungan luar sungai. Untuk melindungi tebing sungai dibuatlah bangunan pelindung tebing. Salah satu material ramah lingkungan untuk pelindung tebing yang akan diteliti adalah bata Interlock yang terbuat dari tanah merah bakar. Bata Interlock adalah material penyusun dinding yang mempunyai pengait pada sisisisinya untuk mengunci pergerakan akibat gaya tekan. Penelitian ini bertujuan untuk mengetahui pengaruh variasi muka air dan ketebalan batu bata interlock terhadap stabilitas lereng bangunan pelindung tebing. Penelitian ini merupakan penelitian kuantitatif melalui pendekatan eksperimen dalam bentuk uji material di Laboratorium Mekanika Tanah dan Mekanika Bahan Universitas Sebelas Maret. Parameter yang dicari berupa parameter dari material tanah dan batu bata interlock. Parameter material mencakup massa jenis, kohesi dan sudut geser dalam. Lalu dari parameter yang dihasilkan akan dilakukan pemodelan menggunakan software geoslope yang akan menghasilkan angka keamanan lereng dari tiap variasi muka air dan ketebalan batu bata Interlock. Berdasarkan pemodelan menggunakan software hec ras dan geoslope, diperoleh ketinggian tebing adalah 7 meter. Dari pengaruh ketinggian section bagian bawah pelindung tebing terhadap stabilitas lereng didapatkan hasil angka keamanan maksimum pada ketinggian section bagian bawah pelindung tebing 2,5 meter sebesar 1,451. Dari pengaruh ketebalan bata interlock terhadap stabilitas lereng didapatkan hasil angka keamanan maksimum pada ketebalan 3 bata sebesar 1,459. Dari pengaruh variasi muka air terhadap stabilitas lereng didapatkan hasil angka keamanan paling kecil pada ketinggian 2 meter dari atas pondasi sebesar 1,347.
\end{abstract}

Kata Kunci : variasi muka air, ketebalan batu bata interlock, stabilitas lereng, bangunan pelindung tebing

\section{Pendahuluan}

Sungai Kedung Keris merupakan sungai yang berbentuk meander. Sungai tipe ini memiliki masalah yang sering dihadapi yaitu erosi atau gerusan pada tebing sungai terutama di daerah tikungan luar sungai. Erosi atau gerusan pada tebing sungai ini menyebabkan terjadinya kelongsoran pada tebing sungai sehingga geometrik saluran akan berubah. Perubahan geometrik sungai ini akan menyebabkan alur sungai berubah.

Ibrahim Hasan (2013) menyebutkan gerusan diakibatkan dari aksi erosif air yang mengalir, yang menggali dan membawa material dari dasar dan lereng sungai. Tanah berbutir lepas dengan cepat tererosi oleh aliran air, sedangkan tanah kohesif lebih tahan terhadap gerusan. Bagian tengah lereng ke bawah adalah bagian yang selalu basah oleh aliran yang akan langsung 
mengalami gerusan, dan jika material lereng tidak tahan terhadap gaya gerus maka terjadi penggerowongan (undermining) yang dapat mengakibatkan terbentuknya kantilever pada lereng dan akhirnya keruntuhan terjadi.

Ika Yuliana (2017) menyebutkan batu bata Interlock adalah material yang dalam pemasangannya tidak memerlukan spesi pengikat karena batu bata interlock ini mempunyai grips yang dapat mengunci antar bata. Selain itu bahan material ini dapat dibuat dari bahan limbah yang tidak terpakai.. Sehingga material batu bata interlock ini tergolong material ramah lingkungan.

Keuntungan penggunaan batako sistem Interlock diantaranya adalah lebih cepat pengerjaan sehingga lebih ekonomis karena tidak menggunakan adukan spesi (mortar) sebagai perekat, selain itu hasil pemasangan lebih rapi, penggunaan acian lebih sedikit serta lebih tahan gempa. Namun demikian, batako sistem Interlock yang berukuran standar masih perlu ditingkatkan dan dikembangkan misalnya dengan merekayasa komposisi dan susunan bahannya serta sistem pengunci saat digunakan sebagai partisi/dinding. Dengan berbagai kelebihannya maka produk batako Interlock yang ringan mempunyai prospek yang bagus untuk digunakan di masyarakat. (Reza Bastari I, 2011).

Perencanaan bangunan pelindung tebing dengan menggunakan batu bata interlock layak untuk diteliti karena sesuai dengan paradigma baru yaitu perencanaan bangunan pelindung tebing yang ramah lingkungan.

\section{Landasan Teori}

Kelongsoran tanah merupakan akibat meningkatnya tegangan geser suatu massa tanah atau menurunnya kekuatan geser suatu massa tanah. Kekuatan geser dari suatu massa tanah tidak mampu memikul beban kerja yang terjadi. Gangguan terhadap stabilitas lereng dapat disebabkan oleh berbagai kegiatan manusia maupun kondisi alam. Lereng yang tidak stabil sangat berbahaya terhadap lingkungan sekitarnya, oleh sebab itu analisis stabilitas lereng sangat diperlukan (Iro Ganda dan Roesyanto, 2012).

Analisis stabilitas lereng adalah suatu perhitungan analisis yang dilakukan pada daerah lereng suatu konstruksi bangunan atau pada tanah asli untuk memberikan informasi mengenai tingkat kestabilan lereng yang sering kali dinyatakan dalam suatu koefisien dengan membandingkan jumlah gaya atau momen pendorong dengan jumlah momen yang menahan. Adapun hubungan beberapa variasi nilai faktor keamanan terhadap kemungkinan longsoran lereng maupun pada perancangan lereng dapat dilihat pada Tabel 1.

Tabel 1 Hubungan nilai Safety dan kemungkinan kelongsoran lereng tanah (Bowles, 1989) :

\begin{tabular}{cc}
\hline Nilai SF & Kemungkinan Longsor \\
\hline$<1,07$ & Kelongsoran bisa terjadi \\
\hline $1,07<\mathrm{SF}<1,25$ & Kelogsoran pernah terjadi \\
\hline$>1,25$ & Kelongsoran jarang terjadi \\
\hline
\end{tabular}

\section{Metode Penelitian}

Analisis dilakukan dengan menggunakan software HEC RAS untuk menentukan ketinggian muka air banjir dan Geoslope untuk menganilisis faktor keamanan lereng bangunan pelindung tebing. Parameter yang dicari berupa parameter dari material yang diambil dari Sungai kedung keris dan material bata interlock. Parameter material mencakup berat jenis tanah, kohesi tanah, kuat geser dalam tanah, kuat tekan bata interlock, dan massa jenis bata interlock.

\section{Lokasi Penelitian}

Lokasi penelitian adalah lereng Sungai Kedung Keris pada sta 4+50 m dari hilir sungai, Nguter, Sukoharjo yang dapat ditunjukan pada Gambar 1

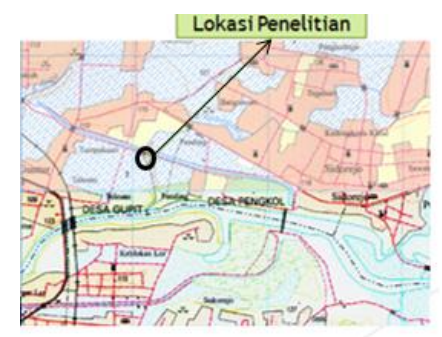

Gambar 1 Denah Lokasi Penelitian

\section{Pemodelan Lereng}

Pemodelan lereng yang dilakukan dengan mengumpulkan data sebagai berikut:
a. Data Tanah
Data tanah lereng Sungai kedung keris diperoleh dari data Primer hasil pengujian sampel tanah di Laboratorium
Mekanika Tanah Universitas Sebelas Maret Surakarta.
b. Data Batu Bata Interlock
Data batu bata interlock diperoleh dari data Primer hasil pengujian sampel batu bata interlock di Laboratorium
Mekanika Bahan Universitas Sebelas Maret Surakarta. 
Beberapa variasi yang dilakukan saat pemasangan batu bata interlock dapat dilihat pada Gambar 2 .

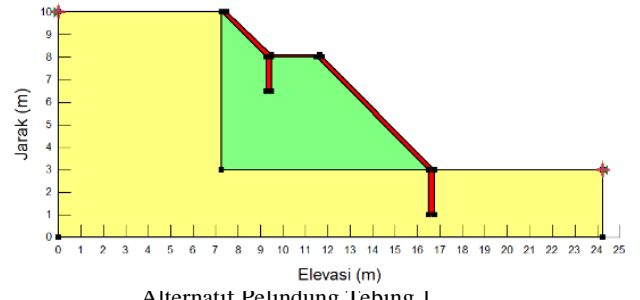

Alternatıt Pelındung lebıng 1

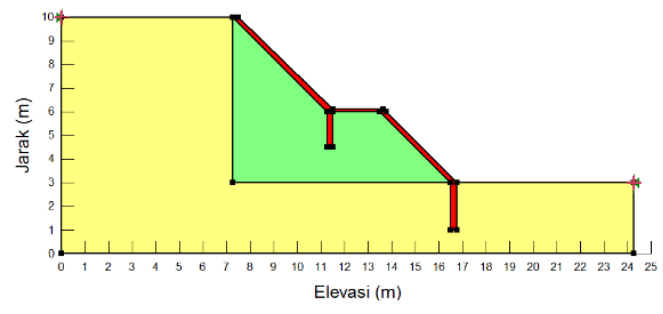

Alternatif Pelindung Tebing 3

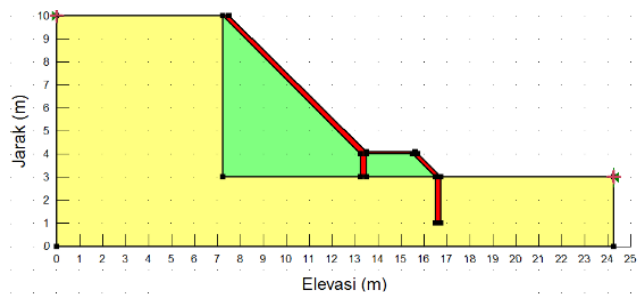

Alternatif Pelindung Tebing 5

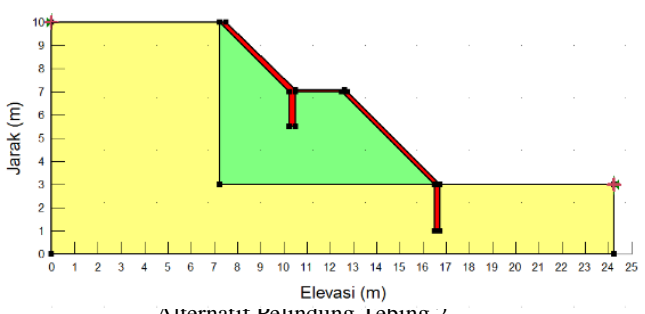

Alternatıt relındung 1 ebıng 2

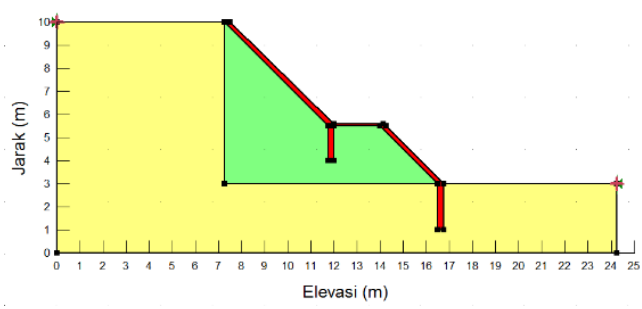

Alternatif Pelindung Tebing 4

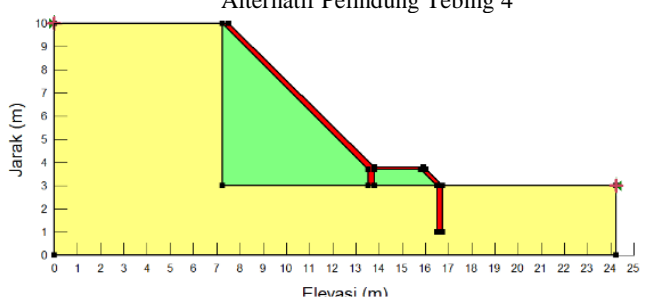

Alternatif Pelindung Tebing 6

Gambar 2 Variasi Pemasangan Pelindung Tebing

\section{Diagram Alir Penelitian}

Diagram alir penelitian dapat dilihat pada Gambar 3

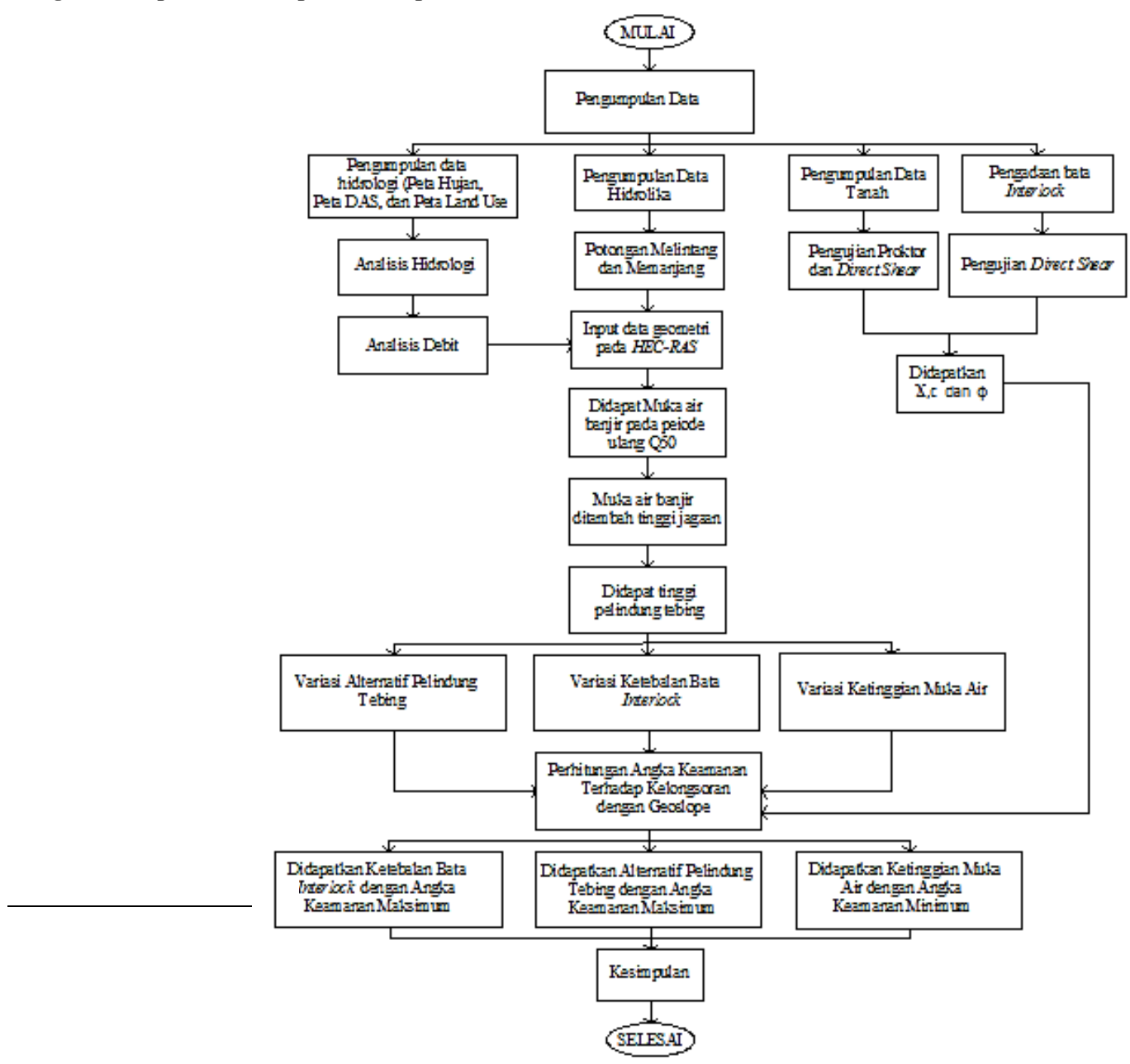




\section{Hasil dan Pembahasan}

\section{Ketinggian Bangunan Pelindung Tebing}

Berdasarkan running program hec ras dengan debit $\mathrm{Q}_{10}$ sebesar 34,04 m3/det didapatkan ketinggian muka air 6 meter, ketinggian tersebut ditambahkan 1 meter tinggi jagaan akan didapatkan ketinggian pelindung tebing setinggi 7 meter.

\section{Data Tanah}

Data tanah diperoleh dari laboratotium Mekanika Tanah Universitas Sebelas Maret. Hasil perhitungan pengolahan data tanah bisa dilihat pada Tabel 2 .

Tabel 2 Data Tanah

\begin{tabular}{cccc}
\hline Parameter Tanah & Satuan & Asli & Timbunan \\
\hline $\mathrm{\gamma}$ & $\mathrm{kN} / \mathrm{m} 3$ & 17,66 & 19 \\
\hline $\mathrm{c}$ & $\mathrm{kN} / \mathrm{m} 3$ & 18 & 44 \\
\hline$\phi$ & $\mathrm{o}$ & 8,68 & 12,39 \\
\hline
\end{tabular}

\section{Data Bata Interlock}

Data tanah diperoleh dari laboratotium Mekanika Bahan Universitas Sebelas Maret. Hasil perhitungan pengolahan data Bata Interock bisa dilihat pada Tabel 3.

Tabel 3 Data Bata Interlock

\begin{tabular}{ccc}
\hline Parameter Bata Interlock & Satuan & Nilai \\
\hline $\mathrm{y}$ & $\mathrm{kN} / \mathrm{m} 3$ & 14,47 \\
\hline $\mathrm{C}$ & $\mathrm{kN} / \mathrm{m} 3$ & 380 \\
\hline$\phi$ & ${ }^{\circ}$ & 11 \\
\hline
\end{tabular}

Hubungan Angka Keamanan Lereng Dengan Ketinggian Section Bagian Bawah Bangunan Pelindung Tebing Rekapitulai perhitungan angka keamanan kelongsoran tanah setelah adanya pelindung tebing menggunakan geoslope bisa dilihat pada Tabel 4.

Tabel 4 Rekapitulasi Hasil Running Program Geoslope variasi ketinggian section bagian bawah bangunan pelindung tebing terhadap stabilitas lereng

\begin{tabular}{ccc}
\hline $\begin{array}{c}\text { Alternatif } \\
\text { Pelindung Tebing }\end{array}$ & $\begin{array}{c}\text { Angka Keamanan } \\
\text { Lereng }\end{array}$ & Keterangan \\
\hline Alternatif 1 & 1,427 & Aman Terhadap longsoran \\
\hline Alternatif 2 & 1,441 & Aman Terhadap longsoran \\
\hline Alternatif 3 & 1,450 & Aman Terhadap longsoran \\
\hline Alternatif 4 & 1,451 & Aman Terhadap longsoran \\
\hline Alternatif 5 & 1,444 & Aman Terhadap longsoran \\
\hline Alternatif 6 & 1,439 & Aman Terhadap longsoran \\
\hline
\end{tabular}

Dari hasil rekapitulasi perhitungan alternatif pelindung tebing menggunakan bata interlock didapatkan nilai angka keamanan terendah pada alternatif pelindung tebing 1 yaitu 1,427, sedangkan nilai angka keamanan tertinggi pada alternatif pelindung tebing 4 yaitu 1,451. Pada alternatif pelindung tebing 5 dan 6 angka keamanan cenderung menurun. Dari hasil tersebut dapat dibuat Grafik pada Gambar 4. 


\section{Grafik Hubungan Ketinggian Section Bagian Bawah Pelindung Tebing dengan Angka Keamanan}

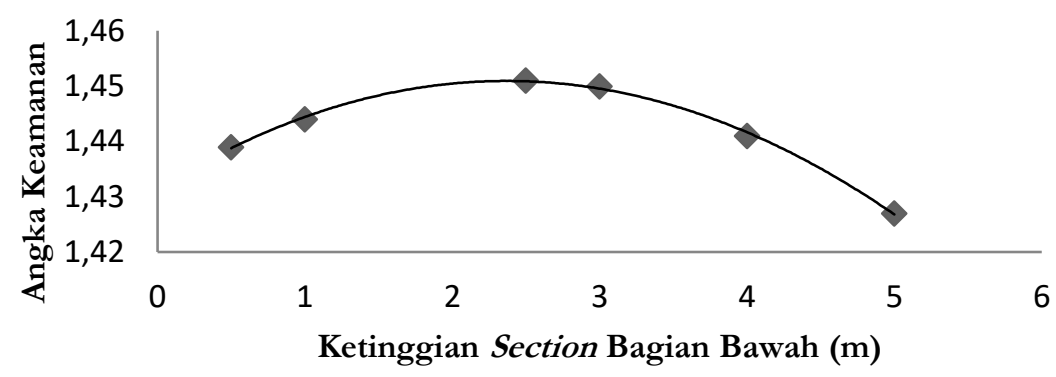

Gambar 4 Grafik Hubungan angka keamanan dengan ketinggian section bagian bawah pelindung tebing

Hubungan Angka Keamanan Dengan Ketebalan Batu Bata Interlock

Rekapitulai perhitungan angka keamanan variasi ketebalan bau bata interlock terhadap stabilitas lereng bangunan pelindung tebing bisa dilihat pada Tabel 5 .

Tabel 5 Rekapitulasi Hasil Running Progran Geoslope variasi ketebalan bata interlock terhadap stabilitas lereng

\begin{tabular}{ccc}
$\begin{array}{c}\text { Ketebalan } \\
\text { Bata Interlock }\end{array}$ & $\begin{array}{r}\text { Angka Keamanan } \\
\text { Lereng }\end{array}$ & Keterangan \\
\hline 1 Bata & 1,446 & Aman Terhadap longsoran \\
\hline 2 Bata & 1,451 & Aman Terhadap longsoran \\
\hline 3 Bata & 1,459 & Aman Terhadap longsoran \\
\hline
\end{tabular}

Dari hasil rekapitulasi perhitungan alternatif pelindung tebing menggunakan bata interlock didapatkan angka keamanan terendah pada ketebalan 1 bata yaitu 1,446, sedangkan angka keamanan tertinggi pada ketebalan 3 bata yaitu 1,459.

Hubungan Angka Keamanan dengan Variasi Ketinggian Muka Air

Rekapitulai perhitungan angka keamanan variasi ketinggian muka air terhadap stabilitas lereng bangunan pelindung tebing bisa dilihat pada Tabel 6 .

Tabel 6 Rekapitulasi Hasil Running Program Geoslope variasi ketinggian muka air terhadap stabilitas lereng

\begin{tabular}{ccl}
\hline $\begin{array}{c}\text { Variasi Muka } \\
\text { Air }\end{array}$ & $\begin{array}{c}\text { Angka Keamanan } \\
\text { Lereng }\end{array}$ & Keterangan \\
\hline Variasi 1 & 2,193 & Aman Terhadap longsoran \\
\hline Variasi 2 & 1,574 & Aman Terhadap longsoran \\
\hline Variasi 3 & 1,349 & Aman Terhadap longsoran \\
\hline Variasi 4 & 1,400 & Aman Terhadap longsoran \\
\hline Variasi 5 & 1,184 & Aman Terhadap longsoran \\
\hline
\end{tabular}

Dari hasil rekapitulasi perhitungan alternatif pelindung tebing menggunakan bata interlock didapatkan nilai angka keamanan tertinggi pada variasi muka air 1 yaitu 2,193, sedangkan nilai angka keamanan terendah pada variasi muka air 3 yaitu 1,349. Pada variasi muka air 4 dan 5 angka keamanan cenderung naik. Dari hasil tersebut dapat dibuat Grafik pada Gambar 5. 


\section{Grafik Hubungan Angka Keamanan dengan Variasi Ketinggian Muka}

Air

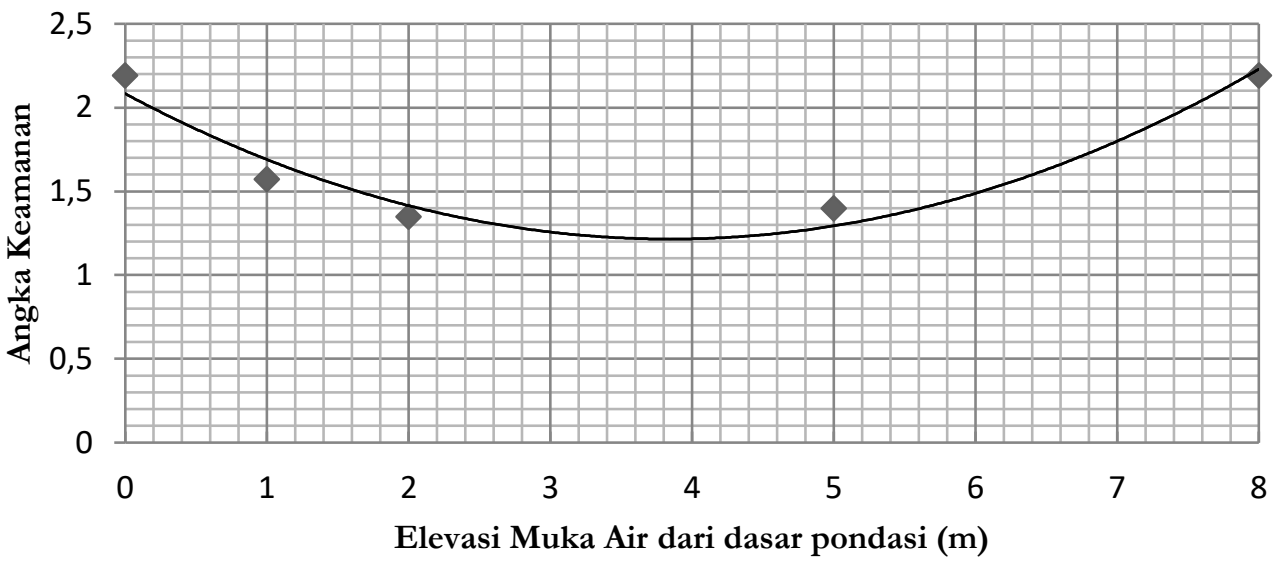

Gambar 5 Grafik Hubungan angka keamanan dengan variai muka air

\section{Kesimpulan}

Berikut adalah kesimpulan yang dapat diambil dari penelitian ini, antara lain :

1. Ketinggian bangunan pelindung tebing untuk sungai Kedung Keris adalah 7 meter

2. Berdasarkan pemodelan stabilitas perkuatan lereng dengan variasi ketinggian potongan pelindung tebing menggunakan aplikasi geoslope menghasilkan angka keamanan (SF) paling besar pada alternatif pelindung tebing 4 yang memiliki potongan pelindung tebing pada ketinggian 2,5 meter sebesar 1,451. Berdasarkan tabel 1 tentang nilai Safety Factor untuk perancangan lereng, kondisi lereng ini aman dari kelongsoran karena SF $>1,25$

3. Berdasarkan pemodelan stabilitas perkuatan lereng dengan variasi ketebalan bata Interlock menggunakan alternatif pelindung tebing 4 pada aplikasi geoslope menghasilkan angka keamanan (SF) yang paling besar pada pelindung tebing dengan ketebalan 3 bata sebesar 1,459. Berdasarkan tabel 1 tentang nilai Safety Factor untuk perancangan lereng, kondisi lereng ini aman dari kelongsoran karena SF $>1,25$

4. Berdasarkan pemodelan stabilitas perkuatan lereng dengan variasi muka air pada pelintindung tebing alternatif 4 ketebalan 3 bata menggunakan aplikasi geoslope menghasilkan angka keamanan (SF) paling rendah pada pelindung tebing alternatif 4 ketebalan 3 bata dengan ketinggian muka air 2 meter dari dasar pondasi sebesar 1,349. Berdasarkan tabel 1 tentang nilai Safety Factor untuk perancangan lereng, kondisi lereng ini aman dari kelongsoran karena SF > 1,25

\section{Daftar Pustaka}

Bowles, A.W.(1989) Sifat sifat Fisik dan Geoteknis Tanah, Jakarta : Erlangga

Ibrahim, Hasan. (2013). Keruntuhan Tebing Saluran dan Sungai Serta Teknik Penanganannya.Diambil dari : https://ibrahimhasan.id/2013/03/26.doc (26Maret 2013)

Ika Yuliana, (2017). Analisis Bata Interlock Sebagai Alternatif Baban Pelindung Tebing Sugai yang Ramab Lingkungan (Studi Kasus Kali Pepe Surakarta).Skripsi. Program Studi Teknik Sipil. Fakultas Teknik. Universitas Sebelas Maret. Surakarta.

Iro Ganda dan Roesyanto, 2012. Analisis Stabilitas Lereng Menggunakan Perkuatan Geogrid (Studi Kasus Jalan MedanBerastagi, Desa Sugo). Universitas Sumatera Utara, Medan

Reza Bastari I,dkk (2011), Potensi penerapan self-locking wall pada pemanfaatan limbah sludge deinking industri kertas sebagai batako interlock, Diambil dari: http://jurnalselulosa.org/index.php/ (2 Juni 2011) 